\title{
86 beautiful dead bodies: gender, migration and representation in anti-trafficking campaigns
}

\author{
Rutvica Andrijasevic
}

\section{abstract}

This essay addresses the link between sex trafficking and European citizesnhip by examining several anti-trafficking campaigns launched in post-socialist Europe. In illustrating which techniques are used in the production of images, it points to the highly symbolic and stereotypical constructions of femininity (victims) and masculinity (criminals) of eastern European nationals. A close analysis of female bodies dispayed in the campaigns indicates that the use of victimizing images goes hand in hand with the erotization of women's bodies. Wounded and dead women's bodies are read as attempts to stabilize the current political and social transformations in Europe by capturing women within the highly immobile boundaries of the sign 'Woman'. The essay suggests that the representation of violence is thus violent itself since it confirms the stereotypes about eastern European women, equates the feminine with the passive object, severs the body from its materiality and from the historical context in which trafficking occurs, and finally confines women within the highly disabling symbolic register of 'Woman' as to maintain an imaginary social order in Europe.

\section{keywords}

sex trafficking; Europe; migration; citizenship; voyeurism 
1 See IOM's web page http://www. iom.int/en/who/ main_mission.shtml.

\section{introduction}

Since the late 1990s, posters and brochures warning about the dangers of trafficking have appeared in nearly all states of East, South-East Europe and former Soviet Union (fSU). The distribution formats of the campaigns are varied and include indoor and outdoor posters (on buses and billboards), leaflets, flyers, postcards, stickers, shopping bags and pocket-calendars. Radio and TV advertisements or documentary films are also part of these campaigns. The campaigns are for the most part conceptualized and realized by the International Organization for Migration (IOM), one of the main Europe-wide actors in developing counter-trafficking programmes, consulting governments on antitrafficking policies and conducting research on trafficking for the sex industry. As an intergovernmental agency, IOM collaborates closely with national governments as well as with the European Commission ( $(\mathcal{C})$, the Organization for the Security and Cooperation in Europe and various branches of the United Nations. The last 'European Conference on Preventing and Combating Trafficking in Human Beings' that took place in Brussels in September 2002 offered the best example of the significance of IOM's role in Europe. The conference, entitled A Global Challenge for the 21st Century, was held under the auspices of the IOM and the $E C$ and aimed at setting the agenda for European anti-trafficking policies. IOM's counter-trafficking work is one among the seven main areas of intervention in the field of the so-called 'migration management', which constitutes the main objective of IOM's work. ${ }^{1}$ These counter-trafficking campaigns aim at raising awareness about trafficking in women by addressing both the general audience as well as selected target groups such as potential victims of trafficking, policy makers, law enforcement officers and relevant public officials.

Trafficking in women, defined as transportation of persons by means of coercion, deception or force into exploitative and slavery-like conditions is commonly associated with sexual-slavery and organized crime. The measures against trafficking in women are comprised of policies that aim at introducing more stringent criminal legislation and improving international police cooperation, as well as schemes and campaigns geared towards protecting victims and informing young women about the dangers of trafficking. In various countries of Eastern Europe where legislative measures against trafficking are still being developed, the information campaigns constitute a privileged means for the prevention of trafficking. The role of immigration policies and of the gendered coding of labour in upholding the conditions of vulnerability that undocumented migrant women face in the service and sex sectors are often overlooked in these debates.

Mechanisms of migration control consign migrants upon arrival at their destination to sectors of economy where there is a demand for racialized and exploitable migrant labour, in particular to the domestic and sex sectors. As scholars have remarked on several occasions, border controls and visa-regimes 
do not prevent people from moving from their countries of origin nor from reaching the EU (Andreas and Snyder, 2000; Mezzadra and Rigo, 2003). Rather, they increase undocumented modes of travel, the involvement of trafficking networks and profit for third parties (Koslowski, 2001; Andrijasevic, 2003). Furthermore, restrictive residency and labour regulations throughout the $\varepsilon U$ restrain the social and labour mobility of migrant women and permit slavery-like employment practices, particularly in economic sectors that are informal or poorly regulated and where regulatory controls are difficult to enforce (Anderson and O'Connell Davidson, 2003).

Starting with the IOM's campaign in the Czech Republic from 1998-1999, one of the first IOM counter-trafficking campaigns in Eastern Europe, and concluding with a rather recent campaign in the Baltic States (Lithuania, Latvia and Estonia) from 2002, I identify a number of representational strategies and elements common to various IOM campaigns that are repeated from one site of representation to another. These, as I will show, establish a very specific regime of representation of trafficking organized around the dichotomy of victims and criminals. In order to offer a more detailed analysis of this regime of representation, I will complement my analysis of the campaigns in the Czech Republic and the Baltic States with additional examples from IOM campaigns in Ukraine and Moldova in $2001 .^{2}$

Images of female bodies are at the very core of IOM's anti-trafficking campaigns. The campaigns resort to victimizing images of female bodies as a way of warning potential women migrants about the dangers of migration and prostitution, and as a means of empowering them to make informed choices concerning working and travelling abroad. Yet, as I will illustrate in this article, techniques used in the production of victimizing images might have paradoxical effects and even contribute to the objectification of women as they capture women's bodies within stereotypical representations of femininity and hence, demarcate the limits within which women can be imagined as active agents. My analysis of the campaign in the Czech Republic and the Baltic States will show how the representational strategies used in the campaigns in order to convey the danger of trafficking equate women's migration with forced prostitution, encourage women to stay at home, and result in an eroticized and voyeuristic spectacle of women's bodies. By examining the representational strategies that deploy wounded and inanimate female bodies in order to caution migrants about trafficking, I will argue that this type of representation restages the familiar scenario where female bodies are portrayed as passive objects of male violence and are positioned within the spaces of the home and the nation. Next to being signified through entrapped/wounded women's bodies, the dangers of labour migration abroad are also conveyed through various representations of traffickers. As I elaborate in the third section, the images deployed across various campaigns to represent traffickers are far from innocent as they signify
2 I thank IOM offices across eastern Europe for their assistance in providing me with their anti-

trafficking material. 
3 The listed funding institutions are: the US Government, the Ministry of Education and youth Czech Republic and the Ministry of Internal Affairs. The general work of $\mathrm{La}$ Strada CR is funded prevalently by the European Union PHARE/TACIS

Programme; http:// www.ecn.cz/ lastrada/czechia/ index_en.html. trafficking in terms of an impersonal and capillary system of control and foster the assumption of wide criminalization of eastern European societies.

By identifying the construction of femininity and masculinity of eastern European nationals in manners that are highly symbolic and stereotypical, this section suggests that IOM's counter-trafficking campaigns act as sites of contention over boundaries and membership in the European community. My analysis of wounded women's bodies, and in particular of the dead women's body used in the Baltic States campaign are read as attempts to stabilize the current political and social transformations in Europe by capturing women within the highly immobile boundaries of the sign 'Woman'. While globalization and integration are changing employment patterns in Europe and as women in eastern Europe are asserting, through migration, their 'right to exit' the objective conditions that impoverish their lives (Mezzadra, 2001), IOM's counter-trafficking campaigns disclose the anxieties that accompany these transformations and attempt their stabilization through a gendered framework. Women's bodies are, I suggest, once again a site where anxieties about the changing European landscape are played out and where it is possible to detect a yearning for a return to a familiar and reassuring race and gender order in Europe.

\section{representation of women's autonomous migration}

In 1999, IOM produced a large-scale counter-trafficking campaign in the Czech Republic in collaboration with a women's non-governmental organization, la Strada. The campaign made use of four images referring to entertainment, care, waitressing and fashion/modelling work. All images are realized in black and white tonalities and are split vertically into two equal halves. On the left side of the image there is a photograph of a woman and on the right a personal narrative of migration and forced prostitution. Underneath the text there is the phone number of La Strada help-line (in yellow), the logo of the IOM and the names of the funding institutions. ${ }^{3}$ A yellow rectangle imitating a job advertisement is positioned in the upper part of the frame.

In image 1 the text on the right side is structured in the following way. At the outset there is a headline: 'The return home won't be easy', 'Are you sure you know what's waiting for you?', 'Blind faith opens its eyes too late', and in image 2 'Do you think it could never happen to you?'. The headlines are followed by a much longer text written in a smaller letter type where an 'l' narrates her story of migration. In the first section of the text, each of the four characters tells of the desire to migrate and work abroad, the contact with an agency or individual arranging travel and work, the deception upon arrival to destination, and finally the coercion into prostitution. In the second and last 


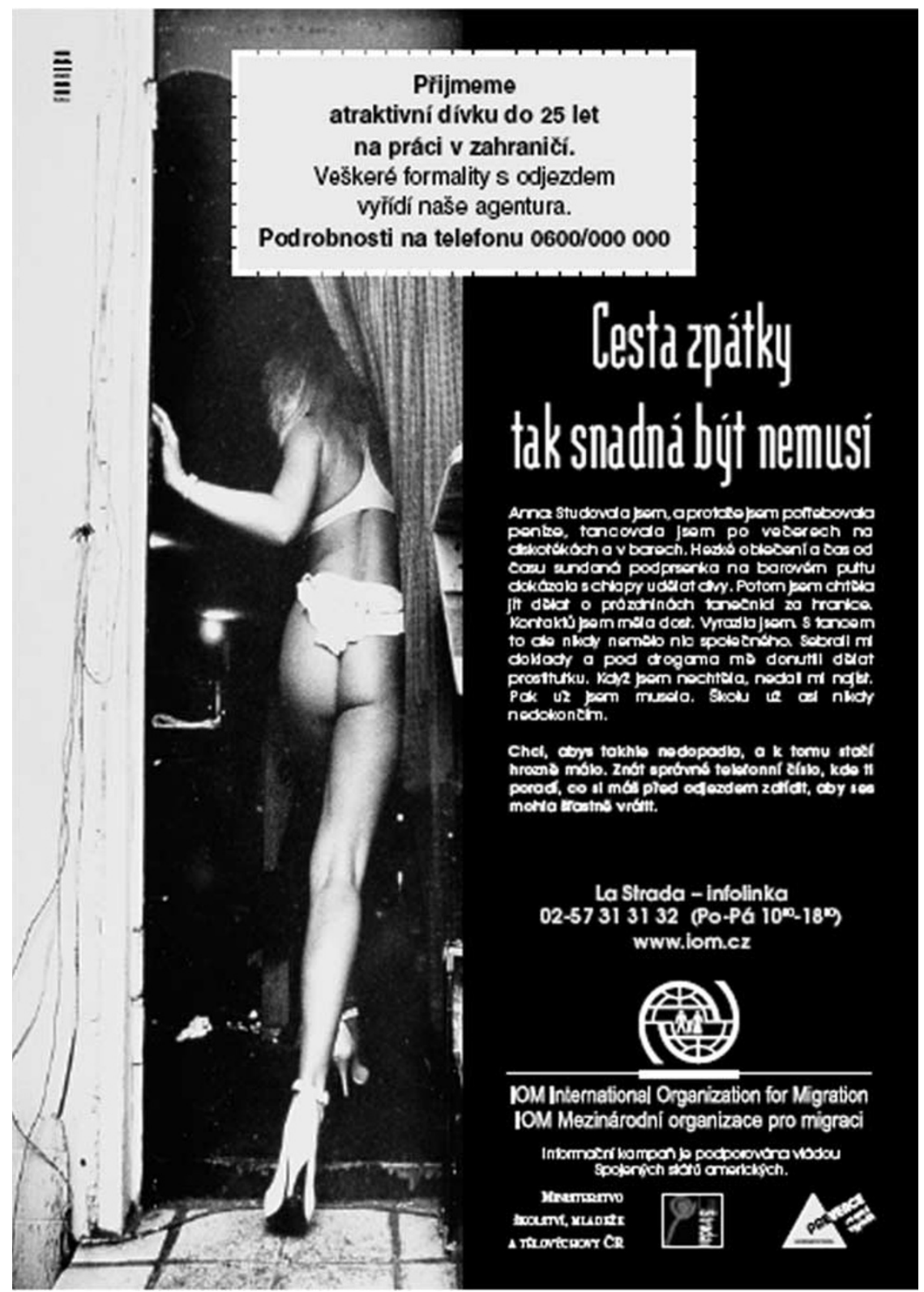

Image 1 IOM Czech Republic campaign (1998)

section written in bold, the story resumes and the readers are warned about the dangers of migration and advised how to migrate safely. Yet, there is no narrative progression in this last section. To say it differently, once the theme of the forced prostitution is introduced in the previous paragraph, the plot ceases 


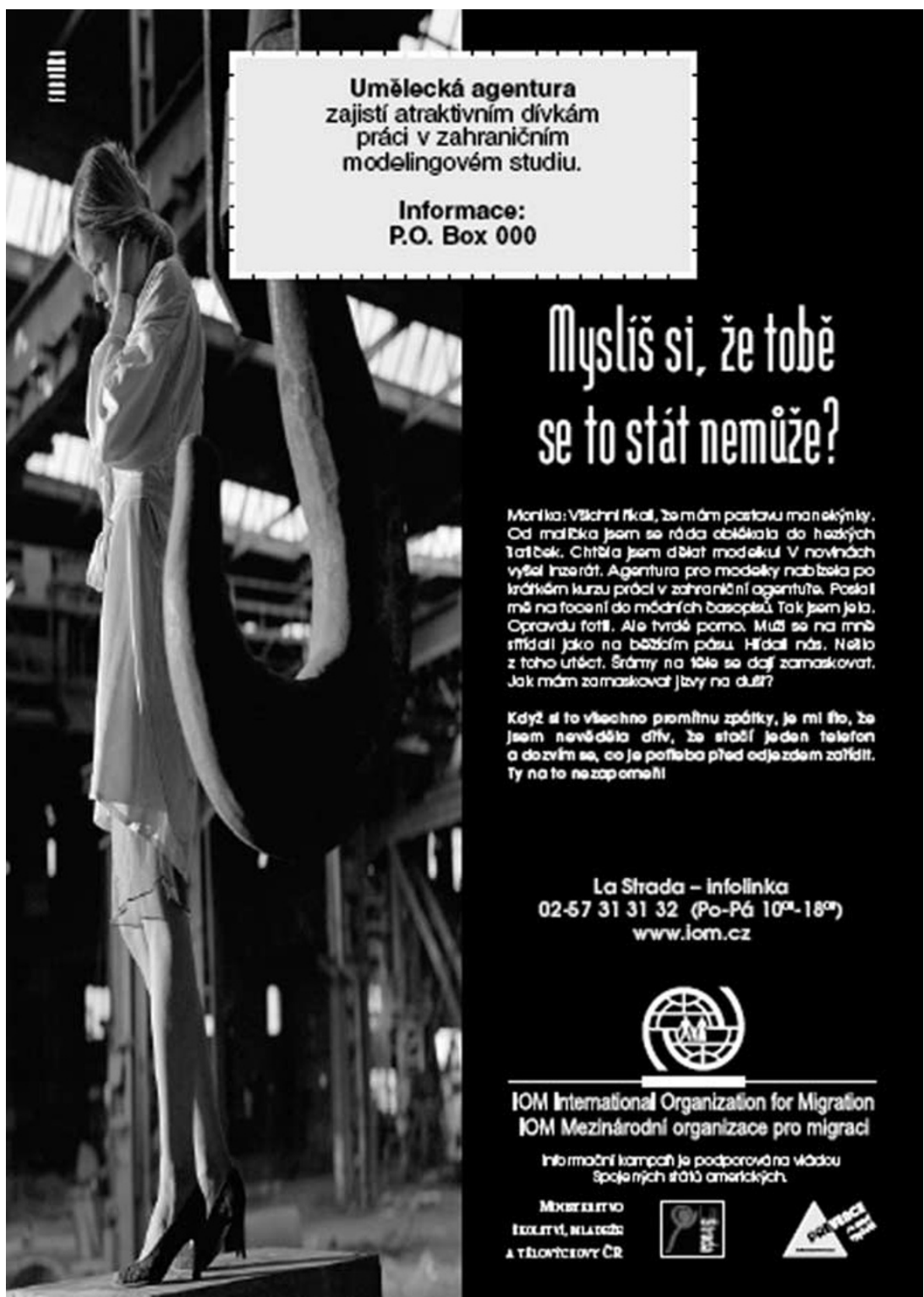

Image 2 IOM Czech Republic campaign (1998)

to advance. For example, in image 2 about work in the fashion industry, the character Monika tells of how she answered an advertisement in the newspaper for working as a model abroad. After a short course, the agency sent her for a photo-shooting abroad, which turned out to be a shooting for a pornographic film. The text in bold reads: 'Men took turns on me like a conveyor belt. They watched me closely, I couldn't escape'. In image 1, addressing the labour 
migration for the entertainment sector, the character-Anna says: 'They took all my documents, drugged me and forced me to work as a prostitute...I will probably never finish school' (image 1). In Monika's and Anna's cases, as in the case of other two characters who migrated for work in care and waitressing but found themselves in the situation of forced prostitution, the absence of progression implies a situation of immobility and entrapment. The introduction of the theme of forced prostitution abruptly interrupts the characters' narrative of hopeful migration and implies that for the four female characters forced prostitution represent the end-stop on their migratory journeys.

The situation of immobility is repeated in the photographs of female figures on the left side of the visuals. The state of entrapment is rendered through the organization of the setting and the figures. It is further enhanced by the dramatic effect achieved through the use of black and white photography and the elongation of the images. The combination of the vertical format and the elongation produces an effect of 'squeezing' through which, as the cultural analyst Anne M. Cronin (2000: 80) explains, the images are framed by the text in order to achieve 'a degree of closure of meaning'. Within the economy of La Strada/IOM visuals, the closure of meaning corresponds to the enclosure of female characters within forced prostitution. A closer look at the composition of setting and photographic techniques used illustrates this point well.

In image 1 , the use of a rather grainy film - a slower speed film - conveys the impression of a worn-out environment and of a 'degrading' activity taking place within it. The appearance of squalor is enhanced by using the keyholeperspective ${ }^{4}$ and narrowing and directing the gaze in a voyeuristic manner to a woman figure whose light skin tone contrasts and separates her from the dark and run-down background. The voyeuristic element is strengthened through positioning the figure slightly off-centre in a way that her bottom becomes the centre of the gaze: a spectator's eye is very dynamically lead along the diagonal line - her right leg - which stretches as the focal point of the composition. The narrow, dark and squalid environment she is about to enter is not the space that invites the viewer to follow her or the space one would like to be in.

In image 2, the situation of immobility is rendered through the fabrication of a state of immobile suspension achieved by cutting off the ground on which the character is standing. This makes it impossible to understand the character's distance from the ground. The state of suspension is further emphasized by the figure's gaze pensively directed downwards. This pose and the absence of the visible ground point possibly to character's wondering whether she should dare a leap. Yet, she is unable to jump because a hook is keeping her in place and prevents her from doing so. Read in combination with the story on the right side of the visual, the image conveys the idea that for this young woman, trapped in the world of hard porn and forced prostitution, escape is not even a remote possibility: 'They watched me closely, I couldn't escape'.

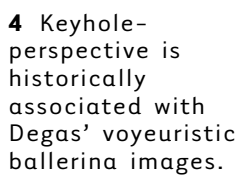

4 Keyholeperspective is historically associated with Degas' voyeuristic ballerina images. 
5 It might be argued that prostitution is included implicitly through the image of a woman working as a dancer in the entertainment industry. However, dancing in a bar does not necessarily mean that one works as a prostitute. In fact, scholars researching sex work have argued that various types of commercial sexual services need to be differentiated in order to avoid sweeping generalizations and have a better understanding of differences
Instead of reading the jump as a leap towards freedom it is possible to read the same movement as a jump into death. The interpretation along the lines of suicide becomes plausible when we refer to the story on the right side: 'In the pictures they covered up my body's scratches and bruises. But how can I conceal the scars on my soul?' Standing commonly for the 'essence' of ones' being, the (wounded) soul impels an understanding of prostitution not merely as a form of physical violence, but also as a type of violence that shatters one's very personhood and from which there is ultimately no recovery. The situation of immobile suspension in the sex industry therefore deprives this young female character of even the most desperate and ultimate escape into suicide, or to phrase it differently, it takes away her control, not only over her life, but also over her death.

As a result of the interplay between the textual and visual frames, La Strada/ IOM's counter-trafficking campaign confines the theme of migration into the realm of forced prostitution. The meaning is articulated between the text and the image and is fixed in a way to identify the most common (and available) forms of women's migration with coerced prostitution. As Stuart Hall (1997: 228) illustrated is his analysis of representational practices, 'two discourses - the discourse of written language and the discourse of photography - are required to produce and 'fix' the meaning'. Even though Anna arranged working as a dancer abroad through her own contacts, Veronika contacted a family who was looking for an au-pair through a newspaper advertisement, Marta was offered a job in a restaurant through an acquaintance, and Monika reacted to a newspaper advertisement placed by a modelling agency, the type of arrangement made a little difference since all of the four characters ended up entrapped in a situation of forced prostitution. Moreover, the campaign leaves out explicit reference to sex work migration, which implies that those who stipulated the contract with the third parties for sex work, are not included nor addressed by this campaign. ${ }^{5}$ Since all the available migration venues lead into coerced prostitution, the campaign implies that the safest option is to remain home. Instead of empowering women to migrate safely, the series is best described as discouraging informal labour migration and advising staying at home as the safest option for young women (Sharma, 2003). By doing so, the campaign places images of women within the traditional representation of womanhood, which positions women outside of the labour market, that is, production, and inside the realm of home thus relegating women to reproduction within the private sphere. Consequently, the La Strada/IOM series upholds the idealization of home as a place devoid of conflict, danger and exploitation.

In conceptualizing the most common and available forms of informal women's labour migration as an inevitable path into forced prostitution, the campaign effaces the fact that next to the domestic/care work, sex work is the most common job venue and source of income for undocumented migrant women in the 
EU. In spite of its best intentions to advise women about the risks of irregular migration, the campaign does not take into account that due to the current restrictive $\mathrm{EU}$ immigration and labour policies it is extremely difficult to obtain working visas for young women from non- $\varepsilon U$ states without major financial backup (Anderson and Phizacklea, 1997; Parreñas, 2001). Additionally, the campaign fails to consider that it is precisely the tightening of the $\varepsilon U$ immigration control and restrictive labour laws that create the conditions for proliferation of trafficking and labour exploitation (Anderson and 0'Connell Davidson, 2003; Berman, 2003; Andrijasevic, 2004).

\section{the narrative of criminals and victims}

In La Strada/IOM campaign, the reader is told that young women have been deceived by agencies or individuals and then coerced into prostitution abroad. The representation of trafficking relies on an extremely simplistic dualism that sets apart young and innocent victims from malevolent traffickers who lure them into migrating abroad. To put it differently, within the discursive economy of trafficking the narrative of women's victimhood is interwoven and contingent upon the narrative of criminality.

In the IOM's campaign launched in Ukraine in 1998, the audience to image 3 is presented with the contours of a gigantic male figure holding a cage with a woman figure in his right hand and money (US dollars) in his left. The headline says: 'Do you want to trade your dignity, your freedom and your health for a cage?' In the IOM's counter-trafficking campaign in Moldova in 2001, image 4 portrays a female figure passed from one hand-visually characterized as male - to another male's hand in exchange of money (US dollars again). Next to the conclusion that US dollars are the main 'hard' exchange currency in the two countries, the visuals imply a link between traffickers and criminal networks as in both cases masculinity is marked by the display of cash, a golden chain bracelet and a signet ring, typical visual codes denoting a pimp or a mafia-man.

In other IOM campaigns, the ideas of danger and control over female bodies are conveyed by signifiers no longer visibly depicted as male. Using the concept of the spider's web, the 2001 IOM campaign from Ukraine represents trafficking in terms of a genderless and all-encompassing threat. In image 5 the male silhouette is substituted by the image of an enormous spider that, signalling the danger of trafficking, has captured a naked female body in its web and is ascending towards it. The naked female figure, with her back turned to the viewer finds itself squeezed between two newspaper advertisements and entangled in the spider's web. The dangers of trafficking are rendered through the interplay of the textual address here conveyed by the heading 'The Web of Trafficking' and the between various types of sex work (Weitzer, 2000:

3-7). 


\section{Хочешь ли ты променять свое достоинство, свободу, здоровье на жизнь в клетке?}

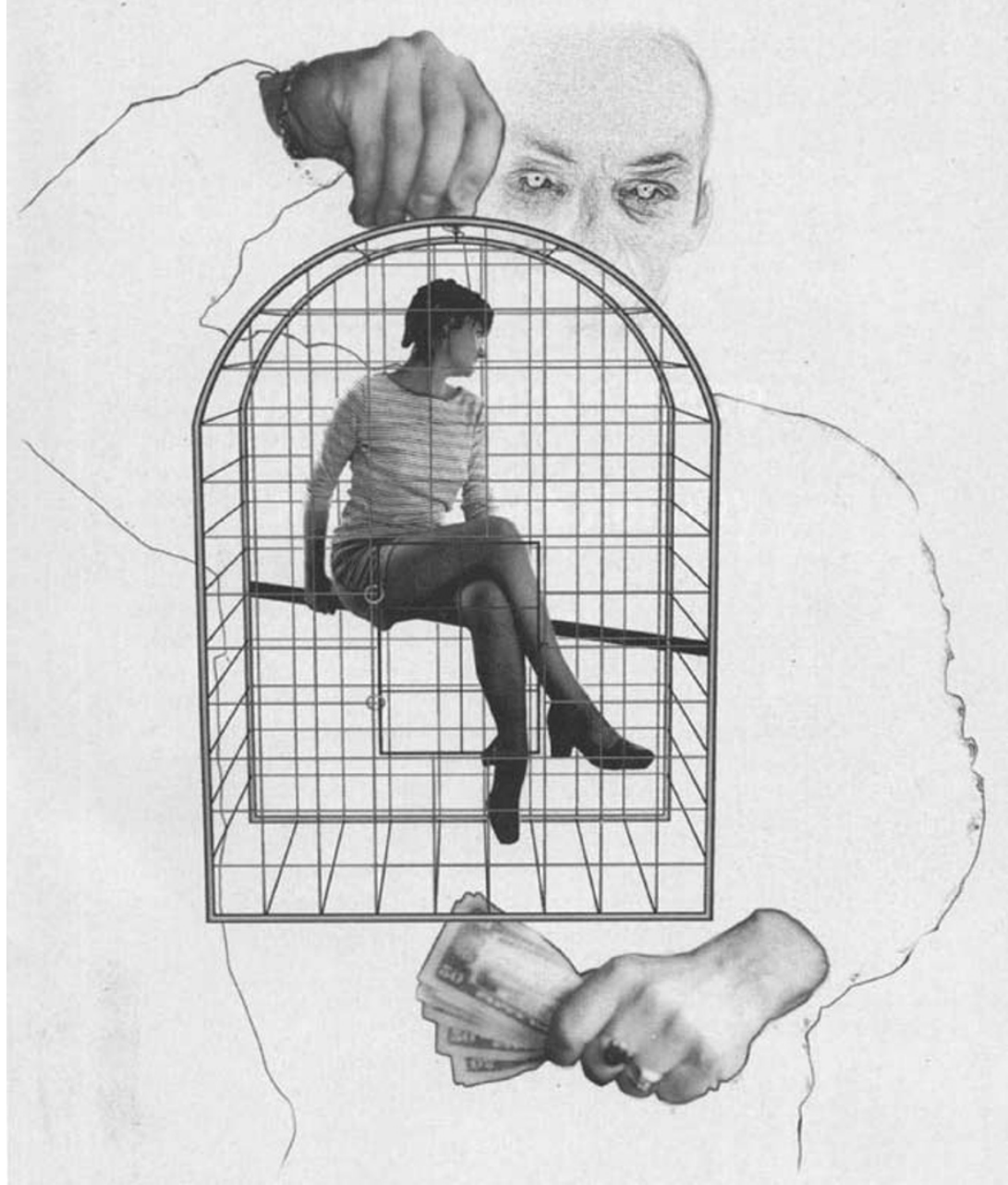

Image 3 IOM Ukraine campaign (1998)

footing 'Ignorance Kills', and by the visual imprisonment of a woman's body in the spider's web with an enormous spider preying on her. In a similar manner, the campaign in the Baltic States makes use of hooks and cords to convey the image of an anonymous and pervasive danger. In image 6 the hooks and ropes that keep the female body hanging in mid-air lead the eye of the viewer outside of the visual frame and hint at the presence of an invisible third party. This absent actor 


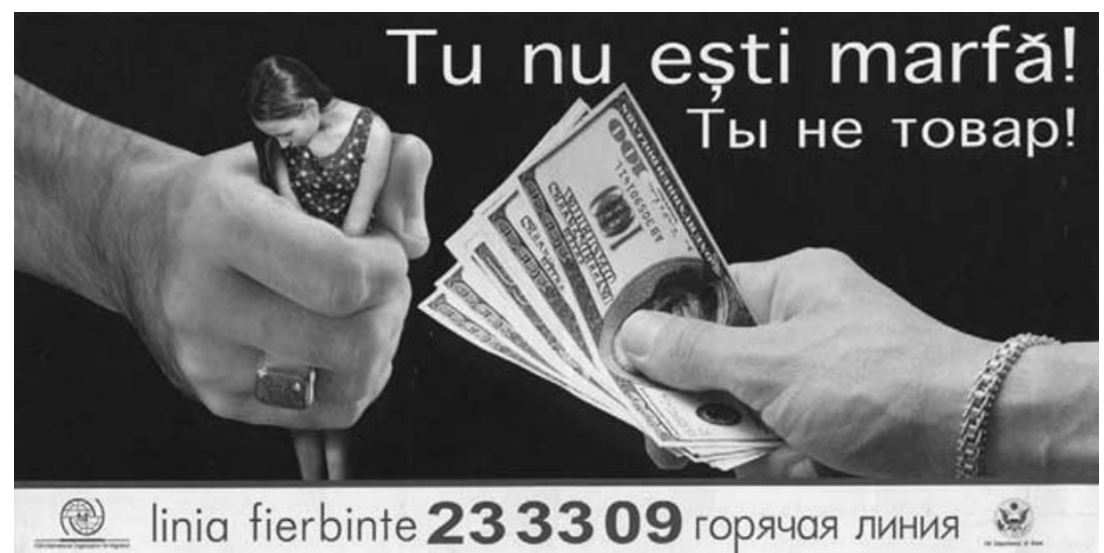

Image 4 IOM Moldova campaign (2001)

is implied as having absolute control over the hanging female figure, directing its moves. Here, as in the campaign featuring a spider, the gender of the trafficker(s) is left unspecified. The representation of trafficker(s) as visibly male has here been substituted by a genderless peril signalled by hooks and cords.

If IOM's campaigns were to represent adequately the fact that third parties are both men and women, as research on trafficking suggests (Maluccelli, 2001; Hopkins and Nijboer, 2004), then the rendering of the variety of third parties required other metaphors in order to avoid the visual collapsing of traffickers with men. In abandoning the heavy golden jewellery and cash in men's hands and proposing instead the depersonalized images, the IOM campaigns from 2001 uncouple the concept of traffickers from its narrow identification with 'Mafiosi' and/or pimps. However, the use of depersonalized images, such as a spider's web and hooks and cords, portray traffickers in terms of an impersonal and capillary system of control over female bodies. Such a representation fosters common assumptions of criminalization of eastern European societies in the post-1989 period and fuels the fear of Russian Mafia's expansion westwards.

In order to convey the condition of abuse perpetuated by traffickers, the campaigns resort to the visual metaphor of the doll as a privileged signifier. This is most clearly visible in the campaign in the Baltic States that makes explicit reference to the doll. The lifeless body, the cords and the 'invisible' third party all invite viewers to associate a victim of trafficking with a puppet. Variations on the theme are also employed, displaying, for example, the same female body in a crouched position or simply body-parts such as hanging legs. In images 7 and 8 two textual captions 'Do not trust easy money abroad' and 'you will be sold like a doll' literally squeeze and fix the body to the referent of the doll. 


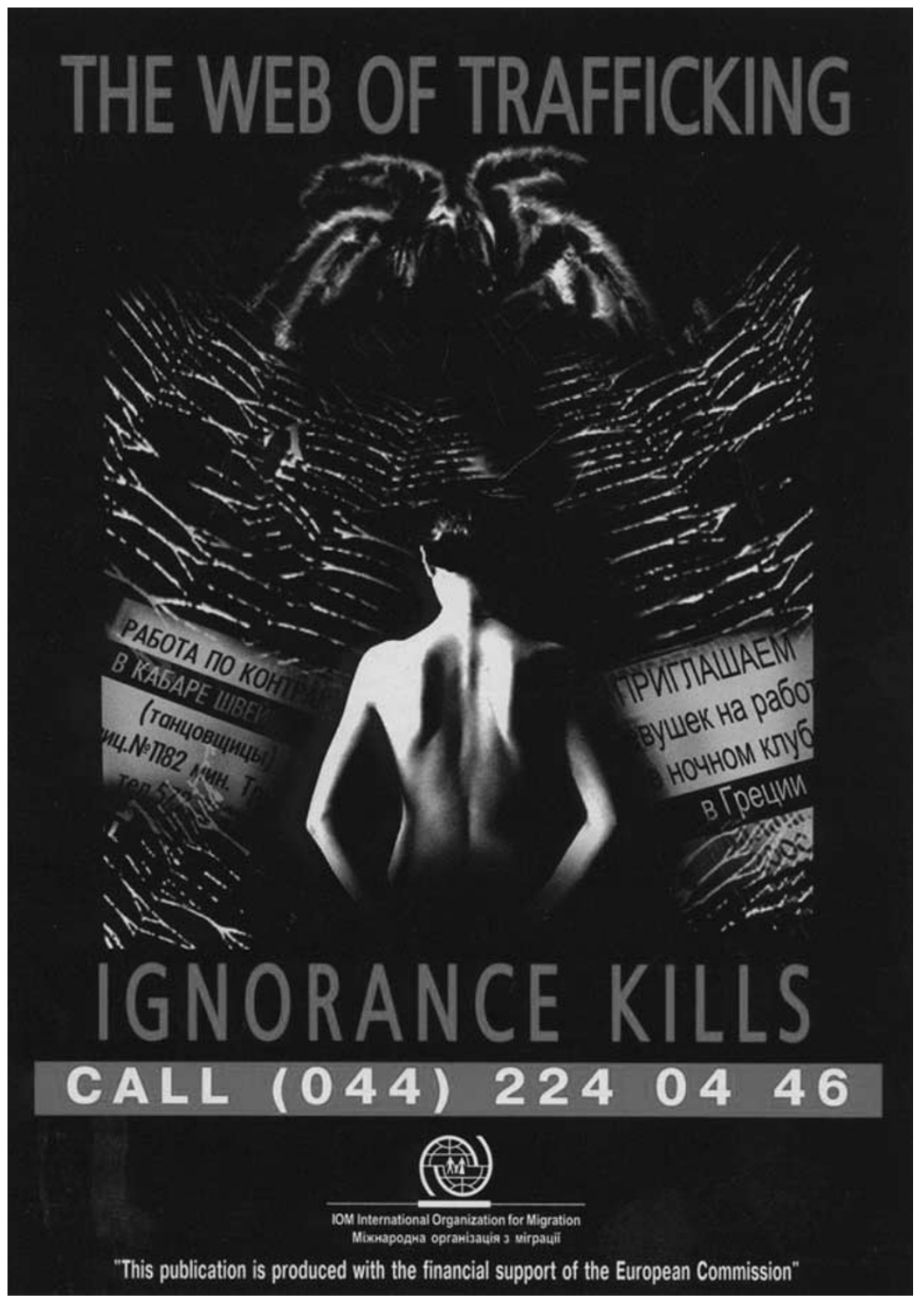

Image 5 IOM Ukraine campaign (2001)

The capture of the female figure within the trope of the doll was intended as such by the campaign's authors in order to convey the lived experience of trafficked women:

The nakedness was meant to show the helplessness and vulnerability of trafficked women. The hooks are visual metaphors used to convey an essential aspect of trafficking, namely 


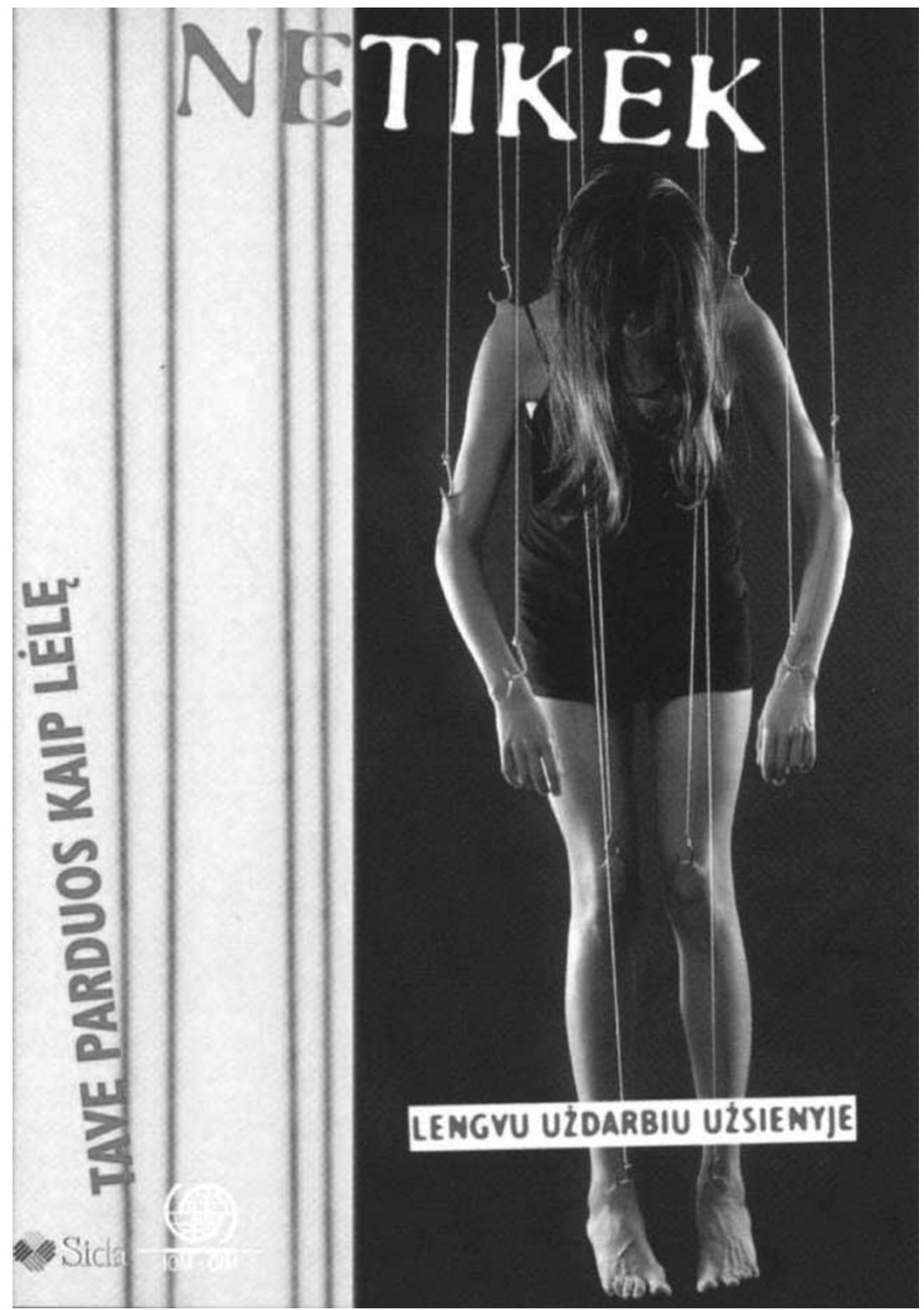

Image 6 IOM Baltic States campaign (2002)

the manipulation and exploitation to which trafficked women are subjected ... Women get beaten, raped, drugged; they are ruthlessly exploited and live in slavery-like conditions handcuffed to beds in squalid enclosures. Some never live to tell their stories because they are killed or take their own lives in desperation... . Most trafficked women find themselves 


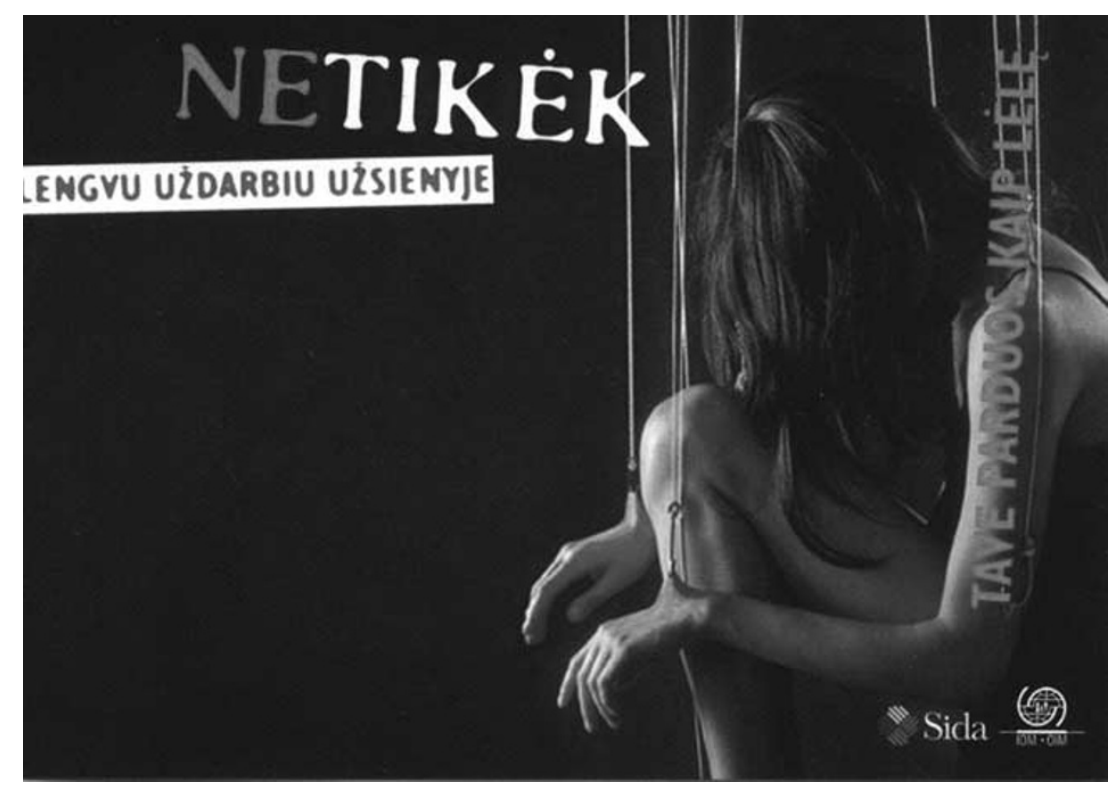

Image 7 IOM Baltic States campaign (2002)

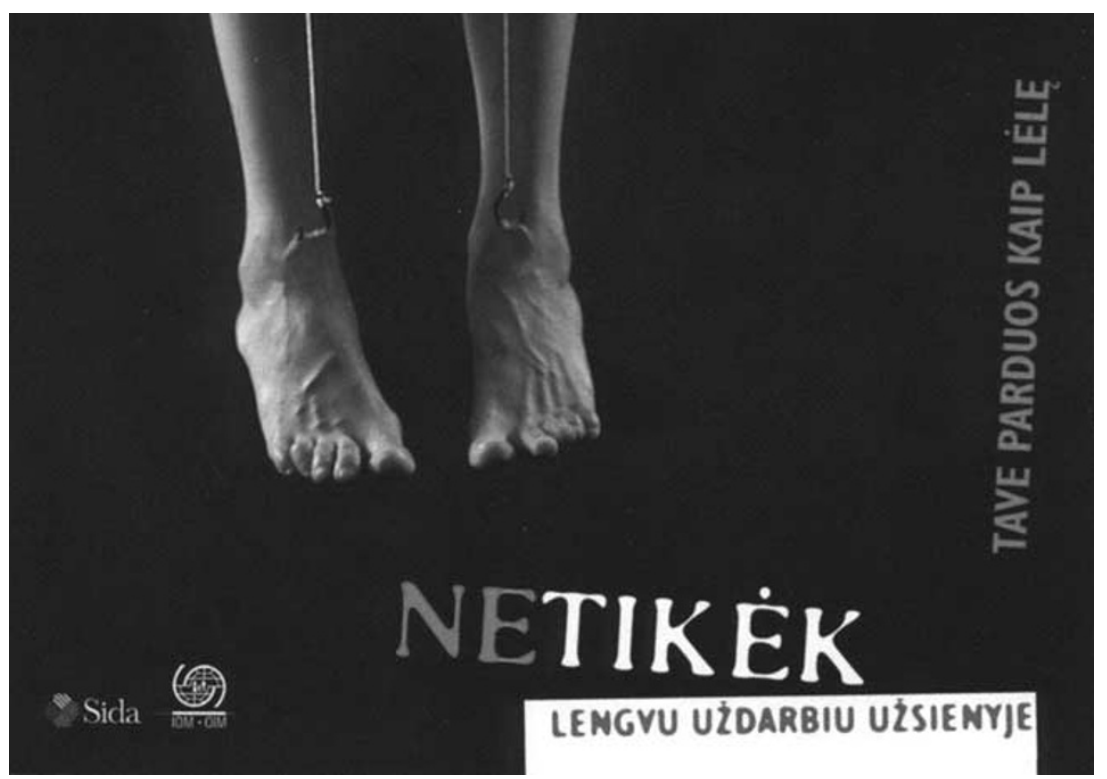

Image 8 IOM Baltic States campaign (2002)

6 The exchange between Ann Jordan and Laurentiu

Ciobanica, IOM's Head of Mass treated as slaves with no control of their lives whatsoever. This is the idea we wanted to convey. ${ }^{6}$

As this quote shows, the construction of women as victims of trafficking resorts to the visual metaphor of the doll in order to convey the abuse, exploitation and 
unfreedom commonly associated with trafficking. Within this framework, the nakedness and the hooks function as visual synecdoches of women's actual experience as such. In other words, IOM's conceptualization of the 'human marionette' is grounded in a project that assumes a straightforward relationship between the reality of women's experiences and its representation.

The operation of conflating the visual images of women and the experience of embodiment is problematic, feminist scholars and artists argue (Reckitt and Phelan, 2001). Feminists have stressed the difference between 'woman as representation' and 'woman as experience'. Women as historical beings and subjects of social relations are not to be confused, feminists have shown, with Woman who is 'purely a representation, a positionality within the phallic model of desire and signification' (De Lauretis, 1987: 20). 'Woman' as representation is a signifier bound by a symbolic order that positions 'her' as Man's irrational Other identified with the body and emotion, devoid of consciousness and confined to immanence (Braidotti, 1994). The representation of women as dolls is part of the patriarchal repertoire of Western culture, a type of 'culture-text' that permeates both high and low culture and is invoked time and again in order to confine the threat of female subjectivity (Meijer, 2002). The nakedness, the cords and hooks used as metaphors in IOM's campaign do not convey so much the resemblance between 'woman as experience' and 'woman as representation' but rather, I suggest, they display the distance between the two and transform women into Woman, an operation that ties woman to her specific place as a bearer of meaning in the symbolic order (see Mulvey, 2003: 44).

By representing women as dolls, IOM's campaigns repeatedly reduce women to 'Woman', thus rendering their actions and desires more controllable and less threatening. At a time of political and symbolic reorganization of the European space, IOM's relaying on signifiers such as dolls can hardy be said to contribute actively to the creation of new images of femininity. Rather, IOM's repertoire organized around the notions of passivity, domesticity and crime impel a representation of eastern European societies in manners that are highly stereotypical, and constrict eastern European women and men within confining and disabling order of representation.

\section{femininity, voyeurism and death}

A mute, inert and scarred female body - a victimized body - stands in IOM's counter-trafficking campaigns for the epitome of objectification: it is a body put on display, a body to be gazed at. ${ }^{7}$ Female figures never look towards the audience: their heads are usually bent in such a way that their hair falls over their faces or they stand with their back turned towards the viewers. The process of looking without being seen in which the passive and violated female bodies cannot return the gaze has been identified by feminist scholars in cinema studies
Information, was posted on the Stop trafficking Mailing List, Vol. 1, no. 44 on 13 th December 2002.
7 Making use of semiotic and psychoanalytic perspectives, feminist and cultural studies scholars have shown that 
there is a sexual element in looking at another person as object and in deriving pleasure from it. Laura Mulvey (2003: 46) has termed the pleasure in looking as 'scopophilia'. with male voyeurism (De Lauretis, 1987; Mulvey, 2003). The voyeuristic aspect is common to most of the campaigns addressed here due to the recurrent display of women's bodies as objects of the gaze, or the use of specific photographic techniques such as the 'keyhole-perspective'. In the image of the human marionette however, it is possible to observe an operation of displacement. Displacement here operates in terms of a transferral of meaning; the scarred skin, only a part of body, functions as a metonymy for the battered/victimized body. This substitution of a part for a whole is characteristic of the practice of fetishism which, as Stuart Hall (1997: 267) points out, is closely linked to disavowal as a 'strategy by means of which a powerful fascination of desire is both indulged and at the same time denied'. The presence of hooks that pierce the body displaces the gaze from the body to the skin and allows the viewer to continue looking while simultaneously disavowing the sexual nature of the gaze.

An additional aspect to the representation of female bodies in the I0M campaigns emerges when we recall that these images refer not only the victims of trafficking but also (and perhaps above all) the victims of forced prostitution. As Hall (1997: 268) puts it in his discussions on Freud and eroticization of the gaze, 'Looking is often driven by an unacknowledged search for illicit pleasure and a desire which cannot be fulfilled'. The female body of the 'human-marionette' acquires its significance exactly through this oscillation between desire and denial that combines in an ambiguous manner the fascination/eroticization of prostitution through skin fetishism and its simultaneous refutation by means of skin ruptures. A reading of bodies through the skin points to IOM's construction of female bodies in terms of sexual(lized) objects shaped by unacknowledged (or perhaps unconscious) perception of (forced) prostitution as erotic. Hence, the production of femininity through representational strategies of victimization and eroticization seems to be intrinsically bound to the female body as a spectacle.

The production of an assaulted female body through scarring of the skin brings to the fore questions of subject formation. Feminist scholars have pointed out that by being an 'outer' layer of the body, skin also functions as a 'boundary-object', which separates the self from the other (Ahmed and Stacey, 2001) or as a 'threshold' of access to other(s) (Irigaray, 1993). Skin as a threshold of access both separates and connects the self with other(s). Within the economy of IOM's campaigns, the encounter with the other assumes a variety of meanings. When the migratory aspect is brought to the fore, then the wounded skin indicates violent/violating encounters with the peoples of different national and cultural identities 'she' came across during her migratory journey. Yet, within the framework of trafficking, the encounter with other(s) is not only about contact with foreign other(s) in terms of culture or nationality but it is also especially about the sexual nature of that exposure. Hence, the assaulted and damaged skin of the human marionette signals a subject whose self has been indelibly wounded as a result of encounters with other bodies. 
Exactly because the skin is characterized, as Sara Ahmed (1998: 36) puts it, by 'the constitutive possibility of a seeping between one and an-other', because it is supposed to keep the 'outside' from becoming 'inside' and 'inside' from becoming 'outside', it is best understood as a 'site of social crisis and instability'. For the threat of insecurity to be contained, the feminine Other that constantly disrupts the categories of difference needs to be restrained. The hooks and ropes perform exactly that function: they keep the female body in place so as to re-establish the binary opposition between self and other and recuperate the hierarchical order in which 'she' is brought under control in the act of capturing her as a 'Woman' (see Bronfen, 1992: 189). The operation of fixing the feminine in a static figure is characteristic of all IOM's campaigns here examined, ${ }^{8}$ but is pushed to its extreme in the campaign from the Baltic States. The position of the head, arms, hands, legs and feet all serve to convey the image of the trafficked woman as an inanimate object. This construction becomes even more evident in images 7 and 8 where the exclusive focalization on the woman's legs and feet prompt the reading of the female body as a dead body.

As for the trope of the doll so the dead feminine body is part of the common image repertoire of Western culture. In her book on death, femininity and the aesthetic, Elisabeth Bronfen (1992) shows that the coupling of femininity and death is a popular and constant theme in literature and painting from the Age of Sensibility to the Modern period. Exactly because the images of feminine death are so familiar and so excessively obvious, explains Bronfen, they often escape our observation. This is even more so because what is actually negotiated over the representation of the dead feminine body is not visible. In fact, both death and femininity are privileged tropes through which culture represses (and articulates) its knowledge of death as well as its desire for immutability. In the representation of death, the existence of death is at the same time acknowledged and repressed precisely because it occurs as an image and is as such confined to the realm of representation, and because it affects someone else's body thus confirming the viewers as living. The feminine as a sign that destabilizes the symbolic register, becomes in death a static figure that signifies Otherness in a stable manner. The sacrificed feminine body, Bronfen elaborates, is a site where the struggle over re-affirmation of boundaries between the self and other and of a threatened order is negotiated: 'Over her dead body, cultural norms are reconfirmed or secured, whether because the sacrifice of the virtuous, innocent woman serves a social critique and transformation or because the sacrifice of a dangerous woman re-establishes an order that is momentarily suspended due to her presence' (Bronfen, 1992: 181).

What is literally represented in IOM Baltic States' campaign, namely the violated female body, 'seeps' through (and exceeds) its representation as to reveal a sense of anxiety over the boundaries of a political community being modified by women's migration, economic 'transition' and European integration.
8 The cage in image 3 , the male hands in image 4 , and the spider's web in image 5 all perform the function of containment and stabilization of woman as a subversive sign. 
The ambivalence and crisis over boundaries is represented by a porous woman's body. If the integrity of the political community is to be regained and its boundaries to be preserved, the female body needs to be secured into a fixed posture and a stable sign. The woman's dead body therefore indicates both a moment of anxiety about the instability of a political community and preserves the illusion of control and security through its stabilization. For the (fantasy of) social order to be re-established, woman is killed symbolically, her subjectivity effaced and turned into a stereotype.

\section{conclusion}

The IOM campaigns aim at warning young women about the risks of (independent female) labour migration and empowering them to make an informed choice by accessing the appropriate information. To this end, the campaigns construct and make use of victimizing images (Ciobanica, 2002). Yet, if we turn to the large body of feminist scholarship and particularly feminist work on the issues of women's representation, what might appear as a straightforward strategy of empowerment becomes a quite controversial and even a badly chosen practice. The term empowerment has always been a crucial concept for feminism and its meaning is most commonly associated to the concept of agency, particularly with regards to enabling women to 'become actors in the world on their own term' (Andermahr et al., 2000: 13). An essential step towards empowerment passes through the recognition of women's experience as the source of (feminist) knowledge, and the unravelling and unfolding of female-feminist genealogies and their recognition as counter-memories. In order for this political transformation to be achieved, feminists stress the importance of developing critiques of existing definitions and representations of Woman as 0ther, re-signifying the sign Woman to affirm the positivity of sexual difference, exposing assumptions about gender (and sex), challenging the misrepresentations and stereotypes of women in images, and revising (art) history through a critical analysis of the representations of racialized and sexualized women's bodies (Rogoff, 2000; Fusco, 2001; Reckitt and Phelan, 2001). For feminist scholars and artists, (political) empowerment - in terms of entitlement practices - is therefore intrinsically linked to challenging stereotyping as a dominant representational practice through the appropriation of negative images, their inscription with new trans-coded meanings (Hall, 1997) and a struggle to find new forms of representation for female subjects.

With these considerations in mind, it is quite difficult to conclude that IOM's counter-trafficking campaigns empower women. The images here discussed do not re-signify dominant representational practices nor do they propose new forms of representation for women. Quite the contrary, they deploy techniques that frame women's body in a voyeuristic manner and lock it into an (im)position of 
immobility. In this way, the IOM's campaigns convey images of unhappy, desperate and suicidal women, and consequently re-install the stereotypical rendering of feminine bodies in terms of passive objects of violence. Moreover, by highlighting the innocence and unwillingness of these young white female bodies, the IOM's campaigns re-propose the conventional trafficking rhetoric. This rhetoric, as Jo Doezema (1992: 2) has shown in her analysis of trafficking in women's media imaginary, is centred upon 'the paradigmatic image ... of a young and naive innocent lured or deceived by evil traffickers into a life of sordid horror from which escape is nearly impossible'. By exaggerating the perils of migration, countertrafficking campaigns identify all prostitution as forced and advocate the private sphere as the safest location for women. Since in IOM's regime of representation, the most common types of women's informal labour migration inevitably lead into forced prostitution, my analysis suggests that IOM's campaigns discourage women's (labour) migration and aim at controlling women's mobility and sexuality by depicting (movement) abroad in terms of a threat and by extension, encouraging the perception of home as safe. Given that 'home' is implicitly portrayed as devoid of danger and thus also of prostitution, IOM's campaigns equate women's place with their sexuality and attempt to regulate the latter by placing women within the familiar space of heterosexual domesticity (see Pollock, 1998: 81-82).

Resorting to 'Woman' as an institution/representation quite paradoxically shows that the control of female sexuality goes hand in hand with its eroticization. The display of suffering and beautiful victims positions the woman's body as the object of the (male) gaze and mobilizes erotic ways of looking that disclose a voyeuristic eroticization and fetishist fascination with a severed/captive female body. The representation of violence is thus itself violent since it confirms stereotypes about eastern European women as beautiful victims, equates the feminine with the passive object, severs the body from its materiality and from the historical context in which trafficking occurs, and finally confines women within the highly disabling symbolic register of 'Woman' as to maintain an imaginary social order.

The female body is, as IOM campaigns show, the site where control over gender hierarchies and the control of geographical territories meet. Just when $\mathcal{U} U$ citizens are encouraged to undertake greater labour mobility, one of the key attributes of the European community, IOM's counter-trafficking campaigns criminalize the labour mobility of women from eastern European non-EU member states and encourage them to remain at home. ${ }^{9}$ The 'technology of gender' put forth by IOM's counter-trafficking campaign - the term advanced by Teresa de Lauretis (1987) to indicate the techniques and discursive practices by means of which gender is constructed and violence engendered - exposes the struggle over the control of women's bodies, sexuality and labour mobility as they accompany the processes of economic 'transition' and integration in the enlarged Europe. At a time of deep social and symbolic reorganization of the European space, IOM's
9 The campaigns in the Czech Republic and the Baltic States, realized respectively in 1998 and 2002 , were developed before these countries' entry into the $\varepsilon U$ in 2004. 
campaign enacts a (discursive) containment that limits the possibilities for creating new images of female subjectivity, criminalize the movement of non- $\varepsilon U$ nationals and hence holds in place and out of the $\varepsilon U$ citizenship, the bodies of eastern European women.

\section{acknowledgements}

I thank Bridget Anderson and the two anonymous reviewers for their thoughtful suggestions on the previous version of this paper. I would also like to acknowledge that the writing of this paper was made possible by the ESRC postdoctoral scheme.

\section{author biography}

Rutvica Andrijasevic is currently an ESRC post-doctoral Fellow at the Centre on Migration, Policy and Society (COMPAS), University of Oxford where she is revising for publication her Ph.D. manuscript entitled Trafficking in Women and the Politics of Mobility in Europe. Rutvica holds a doctorate in Women's Studies from Utrecht University and is specialized in the area of gender, migration, citizenship and asylum with trafficking in women being her main area of expertise. Her work has been widely published in various European languages and journals: DeriveApprodi, Studi Culturali, Multitudes, REMI, Treca, Prokla and Feminist Review. She is part of the NextGENDERation and the Frassanito networks and one of the organizers of the NextGENDERation activities at European Social Fora in 2002, 2003 and 2006.

\section{references}

Ahmed, S. (1998) 'Tanning the body: skin, colour and gender' New Formations, Vol. 34: 25-40.

Ahmed, S. and Stacey, J. (2001) 'Introduction: dermographies' in Ahmed, S. and Stacey, J. (2001) editors, Thinking Trough the Skin, London and New York: Routledge.

Andermahr, S., Lovell, T. and Wolkowitz, C. (2000) A Glossary of Feminist Theory, London: Arnold Publishers.

Anderson, B. and O'Connell Davidson, J. (2003) Needs and Desires: Is there a Demand for 'Trafficked' Persons? Geneva: IOM.

Anderson, B and Phizacklea, A. (1997) Migrant Domestic Workers: A European Perspective, Leicester: Department of Sociology, University of Leicester.

Andreas, P. and Snyder, T. (2000) editors, The Wall Around the West. State Borders and Immigration Controls in North America and Europe, New York: Rowman and Littlefield.

Andrijasevic, R. (2004) Trafficking in women and the politics of mobility in Europe, Doctoral thesis defended at Utrecht University, The Netherlands.

Andrijasevic, R. (2003) 'The difference borders make: (II)legality, migration and trafficking in Italy among 'Eastern' European women in prostitution' in Ahmed, S., Castaneda, C., Fortier, A. and Sheller, M. (2003) editors, Uprootings/Regroundings: Questions of Home and Migration, Oxford and New York: Berg. 
Berman, J. (2003) '(Un)popular strangers and crisis (Un)bounded: discourses of sex-trafficking, the European political community and the panicked state of the modern state' European Journal of International Relations, Vol. 9, No. 1: 37-86.

Braidotti, R. (1994) Nomadic Subjects. Embodiment and Sexual Difference in Contemporary Feminist Theory, New York: Columbia University Press.

Bronfen, $\boldsymbol{\varepsilon}$. (1992) Over Her Dead Body. Death, Femininity and the Aesthetic, Manchester: Manchester University Press.

Ciobanica, L. (2002) 'New IOM website on trafficking in the Baltic' a message posted on the Stop Traffic mailing list on 13 th December.

Cronin, A.M. (2000) Advertising and Consumer Citizenship. Gender, Images and Rights, London and New York: Routledge.

De Lauretis, T. (1987) Technologies of Gender. Essays on Theory, Film, and Fiction, Houndmills and London: Macmillan Press.

Doezema, J. (1999) 'Loose women or lost women. The re-emergence of the myth of "White Slavery" in contemporary discourses of 'Trafficking in Women', http://www.walnet.org/csis/papers/ doezema-loose. html, accessed 16th April 2007.

Fusco, C. (2001) The Bodies That were not Ours and Other Writings, London and New York: Routledge, in association with in IVA, Institute of International Visual Arts.

Hall, S. (1997) editor, Representation. Cultural Representation and Signifying Practices, London: Sage, in association with the Open University.

Hopkins, R. and Nijboer, J (2004) 'Trafficking in human beings and human rights: Research, policy and practice in the Dutch approach' Human Rights Law Review, Special Issue Spring 2004, 75-90.

Irigaray, L. (1993) in Burke, C. and Gill, G. (1993) trans., An Ethics of Sexual Difference, Ithaca, Ny: Cornell University Press.

Koslowski, R. (2001) 'Economic globalization, human smuggling, and global governance' in Kyle, D. and Koslowski, R. (2001) editors, Global Human Smuggling. Comparative Perspectives, Baltimore and London: The John Hopkins University Press.

Maluccelli, L. (2001) 'Tra schiavitù e servitù: biografie femminili in cerca di autonomia' in Candia, G. et al. (2001) editors, Da vittime a cittadine. Percorsi di uscita dalla prostituzione e buone pratiche di inserimento sociale e lavorativo, Roma: Ediesse.

Meijer, M. (2002) 'Migrerende motieven, pratende poppen' in Baeten, J. and Verstraete, G. (2002) editors, Cultural studies: een inleiding, Nijmegen: van Tilt.

Mezzadra, S. (2001) Diritto di fuga. Migrazioni, cittadinanza, globalizzazione, Verona: Ombre corte.

Mezzadra, S. and Rigo, ع. (2003) 'L'Europa dei migranti' in Bronzini, G., Friese, H., Negri, A. and Wagner, P. (2003) editors, Europa, Costituzione e movimenti sociali, Roma: Manifestolibri.

Mulvey, L. (2003 [orig. 1975]) 'Visual pleasure and narrative cinema' in Jones, A. (2003) editor, The Feminism and Visual Culture Reader, Routledge: London and New York.

Parreñas, S.R. (2001) Servants of Globalization. Women, Migration, and Domestic Work, Stanford: Stanford University Press.

Pollock, G. (1998 [orig. 1988]) 'Modernity and the spaces of femininity' in Mirzoeff, N. (1998) editor, The Visual Culture Reader, London and New York: Routledge.

Reckitt, H. and Phelan, M. (2001) Art and Feminism, London and New York: Phaidon Press Limited.

Rogoff, I. (2000) Terra Infirma. Geography of Visual Culture, London and New York: Routledge.

Sharma, N. (2003) 'Travel agency: a critique of anti-trafficking campaigns' Refuge, Vol. 21, No. 3: 53-65.

Weitzer, R (2000) 'Why we need more research on sex work' in Weitzer, R. (2000) editor, Sex for Sale. Prostitution, Pornography, and the Sex Industry, New York and London: Routledge.

doi:10.1057/palgrave.fr. 9400355 